
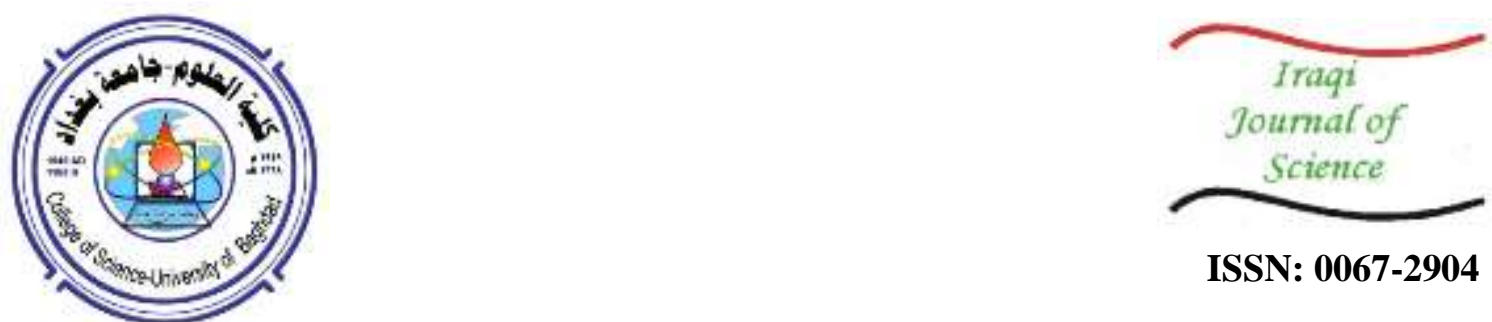

ISSN: 0067-2904

\title{
Antibacterial activity of Some mouthwash Solutions against Staphylococcus lentus Isolated from Mouth Infections
}

\author{
Sameer Abdulameer Alash*, Maoj Qassim Mohammed \\ Department of Biology, College of Science, University of Baghdad, Baghdad, Iraq
}

Received: 2/6/2019 Accepted: 17/7/2019

\begin{abstract}
A total of nine swab samples were collected from inflamed teeth and gingiva of human'soral cavity from a dentist clinic in Baghdad. All specimens were cultured in Mitis Salivarius agar medium and the isolated bacterial pure colonies werethen identified by using VITEK2. Three samples were diagnosed and identified as Staphylococcus lentus. One of the three isolates which showed a distinctive heavy growth on the media was selected for further analysis in this study. Paper disk diffusion method was used to detect the antibacterial activityof three of mouthwash solutions (Zak, Colgate and Listerine). The results showed that "Colgate" was the most active solution with antibacterial activity compared with the other two solutions.
\end{abstract}

Keywords: Staphylococcus lentus; Cetylpyridinium chloride; phenols andsodium fluoride

\section{Staphylococcus lentus الفعالية المضادة للنمو البكتيري لبعض محاليل غسول الفمأتجاه المعزولة من اصابات الفم

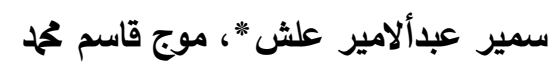

\section{Introduction}

The oral cavity houses various habitats for microorganismswhich support the growth of microbial communitiesin the mucosal surfaces (such as those in the lips, cheek, palate and tongue) and the teeth [1]. Dental plaque is the community of microorganisms found on a tooth surface and it is the agent involved in progression of periodontal and gingival diseases [2]. Development of plaque occurs when food residues that contain carbohydrates are left to accumulate on the teeth for long time. These foods stimulate bacteria in the mouth to thrive and form acids. After a period of time, these acids will 
deteriorate the enamel of the tooth and cause decay. Tooth roots under the gum could be also infected by plaque and cause the bone supporting the tooth to breakdown [3]. Dental plaque symptoms give teeth a fuzzy feeling when touched with the tongue. In the advanced stages, it can manifest as a white, grayish or yellowish coating on the teeth [4]. Plaque buildup can be prevented by a number of practices such asbrushing the teeth at least twice a day with a particular attention to the space where the teeth and gums meet, using fluoride-containingtoothpaste, flossing between teeth at least once a day, using an antibacterial mouth rinse, and consultation by dentist or oral hygienist every six months[5].

Gargling and rinsing the mouth with mouthwashes which are medicated solutions may be recommended for inflammation reduction, infections treatment, pain relief,halitosis reduction, andcaries prevention through the local delivering of fluoride. The preventive use of mouthwashes is mainly to control dental caries and to inhibit or reduce plaque associated bacteria. The most effective ingredients are chlorhexidine gluconate, fluoride, phenol,essential oils and cetylpridinium chloride [6].Staphylococcus lentusis a Gram-positive cocci bacteria which is nonmotile, nonsporing, 0.7-1.2 $\mu \mathrm{m}$ in diameter and occurring singly, in pairs or in tetrads [7]. The cultural characteristics of this bacteria are the S-type and the grayish-white to white or creamy opaque colonies. Some of them are mucoid strains. Colony diameter is about $0.5-5 \mathrm{~mm}$ on $\mathrm{P}$ agar or 2-7 $\mathrm{mm}$ on Tryptic Soy agar. Optimum temperature of growth is between $25-35{ }^{\circ} \mathrm{C}$; no growth could be seen below 15 or above $45^{\circ} \mathrm{C}$. They grow as facultative anaerobes with weakly anaerobic growth; they do not growanaerobically in a thioglycolate media, tardily grow in $10 \% \mathrm{NaCl}$ medium and poorly grow in $15 \% \mathrm{NaCl}$ [8].

Staphylococcus lentus is a member of the Staphylococcus sciuri family which is a common bacterium in the environment; it can be detected from a diversity of animals (domestic, farm and wild) where it commensally colonizes their skins. It was widely detected from food-producing animals that involve domestic fowl and livestock and from their products. Individuals in contact with animals were also found to be bearers of S. lentus. In dairy animals,S. lentuswas shown to be linked with subclinical mastitis and in infrequent cases passed infections to humans. S. sciuri may infect humans and causes severe infections, such as septic shock, bacterial endocarditis, endophthalmitis, pelvic inflammatory diseases, urinary tract infections, incision and wound or abrasion infections [9-11].

The aim of the present study is to detect the actual antibacterial activity of three mouthwash solutions; Listerine, Colgate and Zak against S. lentus.

\section{Materials and Methods}

\section{Solutions (mouthwashes)}

Three types of mouthwashes were bought from a pharmacy in Baghdad:

1. Listerine -fresh burst (Italy), as shown in Figure-1.

2. Colgate plax (Brazil), as shown in Figure-2.

3. ZAK (Egypt), as shown in Figure-3.

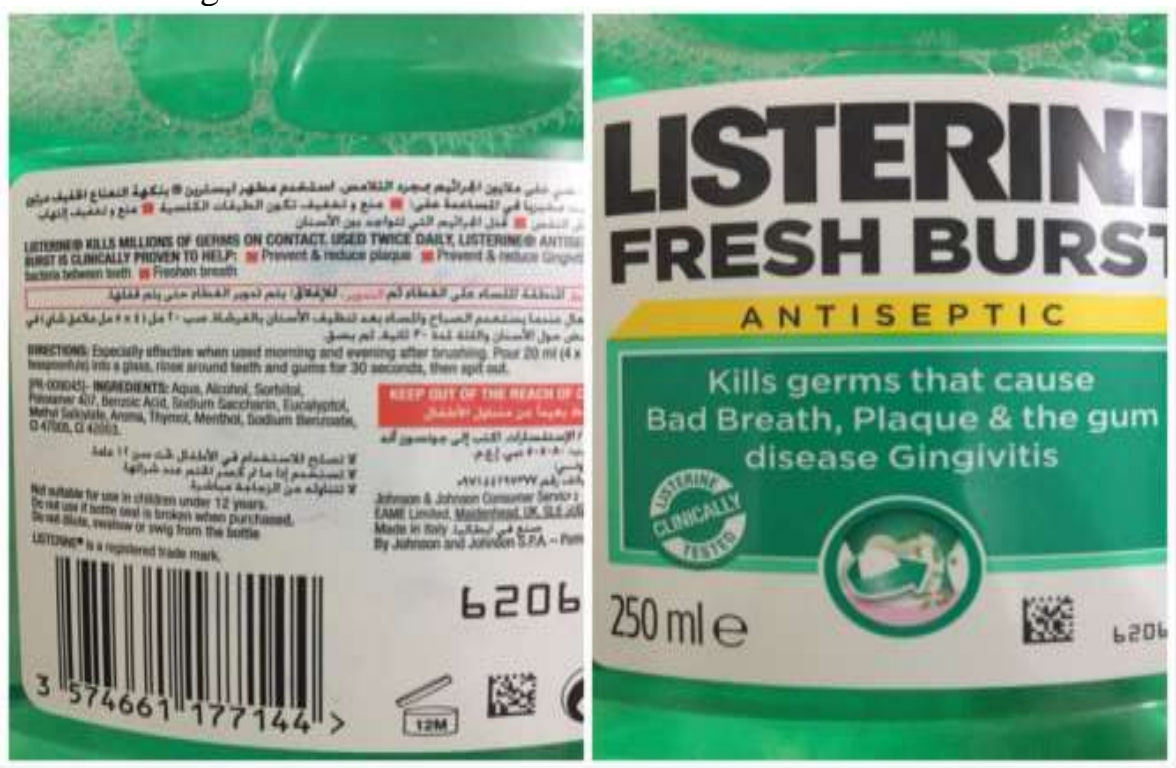

Figure 1-Listerine label 


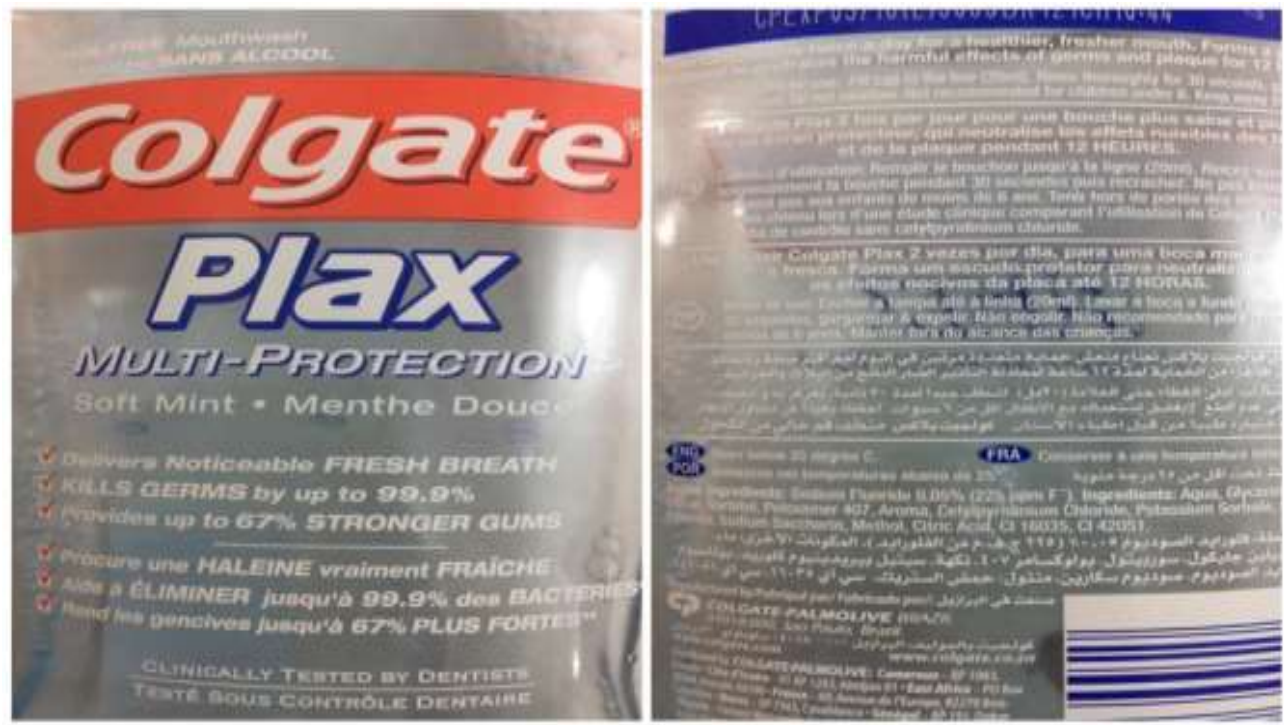

Figure 2-Colgate label
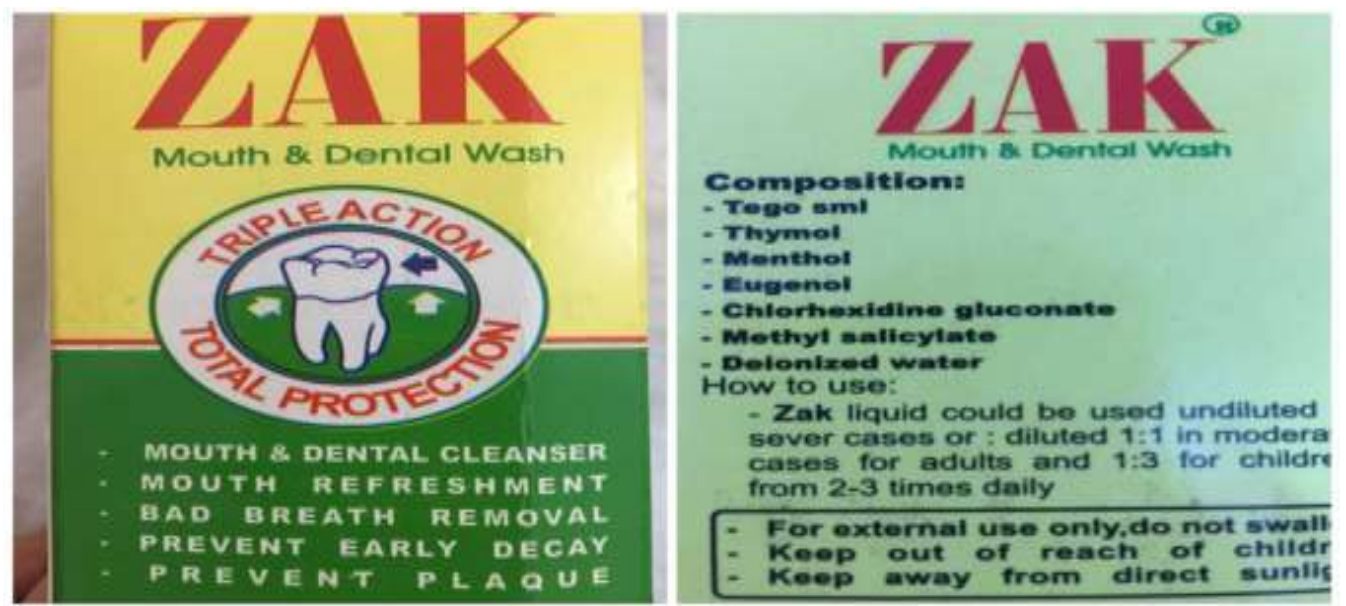

Figure 3-ZAK label

\section{Media}

1. Mitis salivarius agar (Himedia, india).

2. Muller-Hinton agar (Himedia, india).

All media were prepared according to the manufacturing company. $\mathrm{pH}$ was adjusted to be at 7 and sterilization was performed by autoclave $\left(121^{\circ} \mathrm{C} / 15 \mathrm{psi}\right)$ for $15 \mathrm{~min}$. The media were thendistributed into Petri dishes. To ensure the sterility, all dishes were incubated for $24 \mathrm{hrs}$. at $37^{\circ} \mathrm{C}$ and thenstored at $4^{\circ} \mathrm{C}$ until being used.

\section{Samples collection, isolation and diagnosis}

Sterilized swabs and woody stick were used to collect nine samples from human oral cavity. All specimens were cultured and streaked on Mitis Salivarius agar plates, then incubated at $37^{\circ} \mathrm{C}$ under aerobic conditions for 18-24 hrs. After incubation, the pure colonies were selected to be diagnosed by VITEK2 (Nature Eye company).

\section{Mouthwash test}

\section{Mueller-Hinton agar plates preparation}

Mueller-Hinton agar was preparedfollowing the manufacturer's instructions.The medium was cooled to a temperature between $45-50^{\circ} \mathrm{C}$, poured into the Petri-dishes, and allowed to be scaled on a surface to depthlevelof about $4 \mathrm{~mm}$. After the agar was solidified, the plates were dried for immediate use in about $10-30 \mathrm{~min}$. at $25^{\circ} \mathrm{C}$ by placing them in the hood in the upright position with the lids tilted.

\section{Paper Disk Diffusion Method}

The Mueller-Hinton plates were cultured by swab; the swab was rubbed all over the surface of the medium for about four times with rotating at an angle of $90^{\circ}$ after each application. Finally, the swab 
was passed around the edge of the agar surface. The inoculums were left to dry for few minutes at room temperature with a closed lid. Filter paperswere cut into small circles $(10 \mathrm{~mm}$. in diameter $)$ and sterilized by autoclave for 20 minutes. By using sterile forceps, filter papers were transferred to the plates and submerged with mouthwash solutions (the original concentration and without dilution). The plates were labeled and incubated at $37^{\circ} \mathrm{C}$ for $18-24 \mathrm{hrs}$.

\section{Results and Discussion}

Within nine specimens, only three isolates were identified as Staphylococcus lentus (Figure -4). One of these isolates was selected, according to the distinctive heavy growth on media, to be the used isolate in this study (Figure-5). After the end of the incubation periodof the selected isolate on Mueller-Hinton agar, the results showed that the mouthwash Colgatewas the most active solution which caused an inhibitory zone of about $4 \mathrm{~mm}$. in diameter, followed by $\operatorname{ZAK}(3.7 \mathrm{~mm}$.), and Listerine $(0.5 \mathrm{~mm}$.) Figures- $(6,7,8)$. The inhibition zones of each plate were measured in millimeters by the aid of a metric ruler.

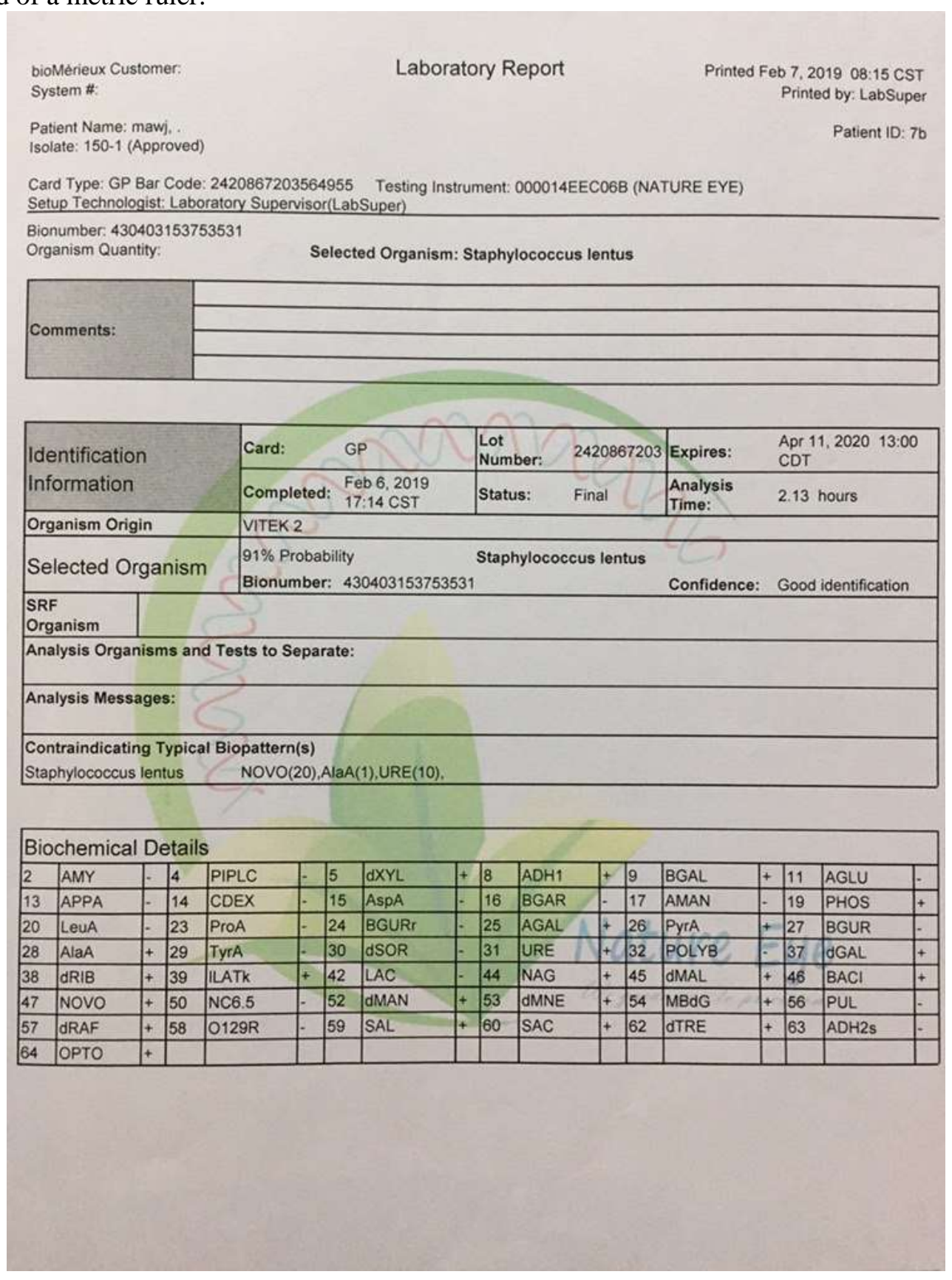

Figure 4-VITEK 2 diagnosis of Staphylococcus lentus 


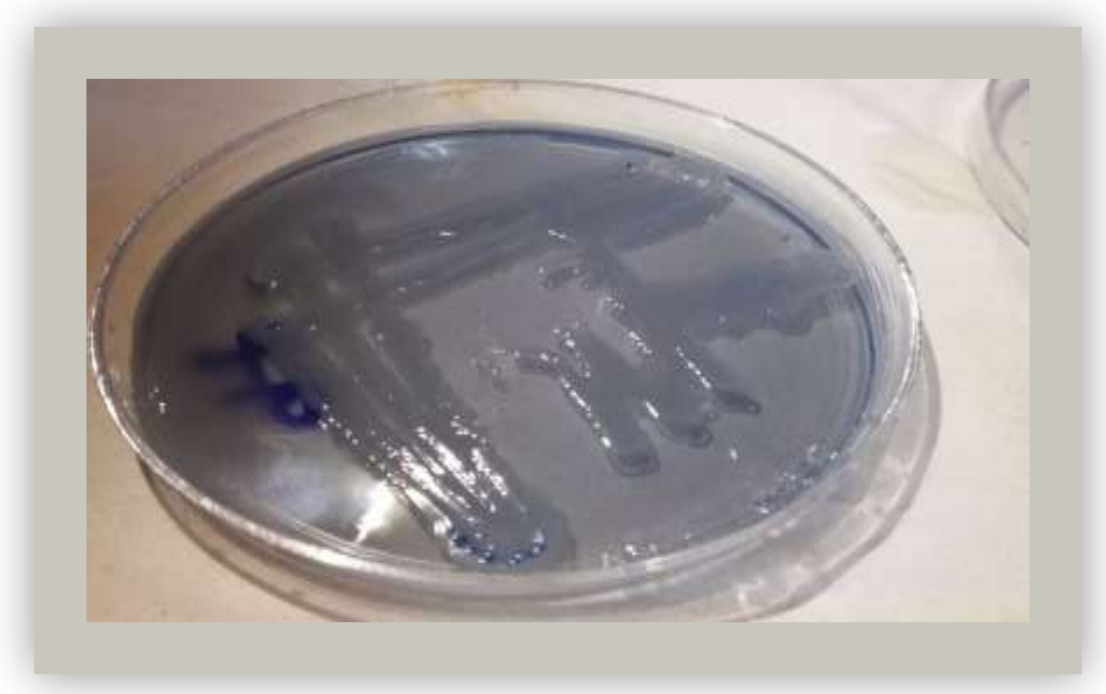

Figure 5-Staphylococcus lentus growth onMitis Salivarius agar

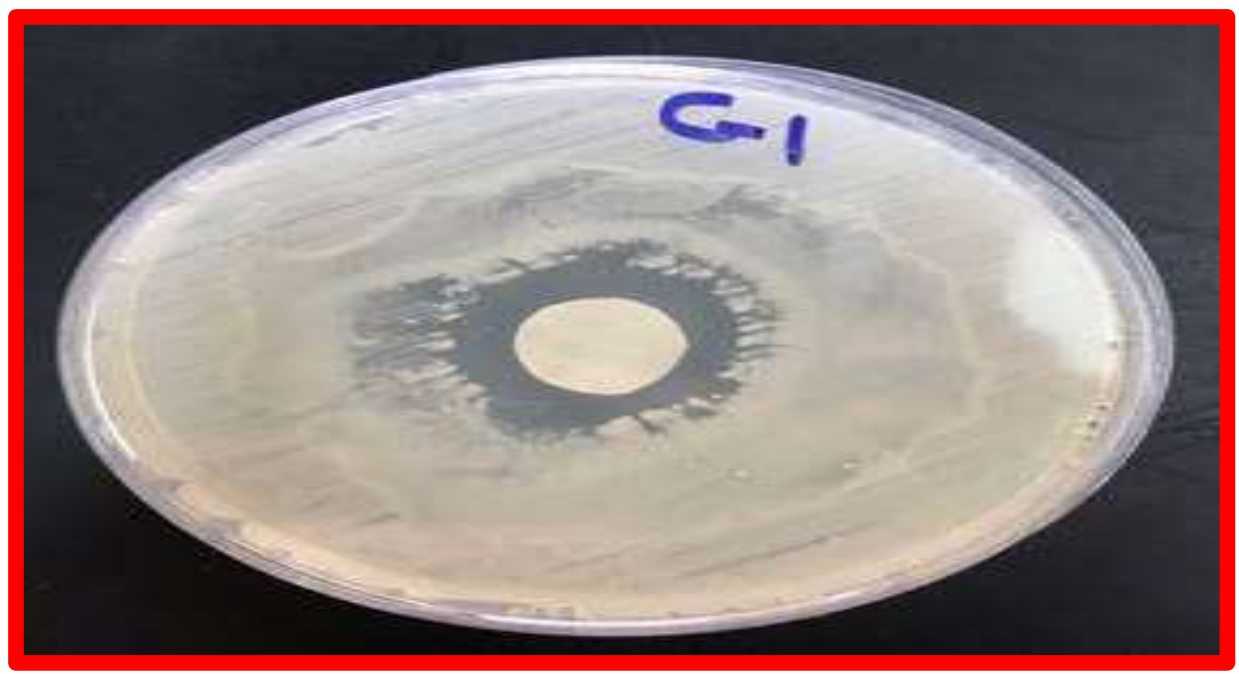

Figure 6- The inhibition zone of Colgate against Staphylococcus lentus growth onMuller-Hinton agar

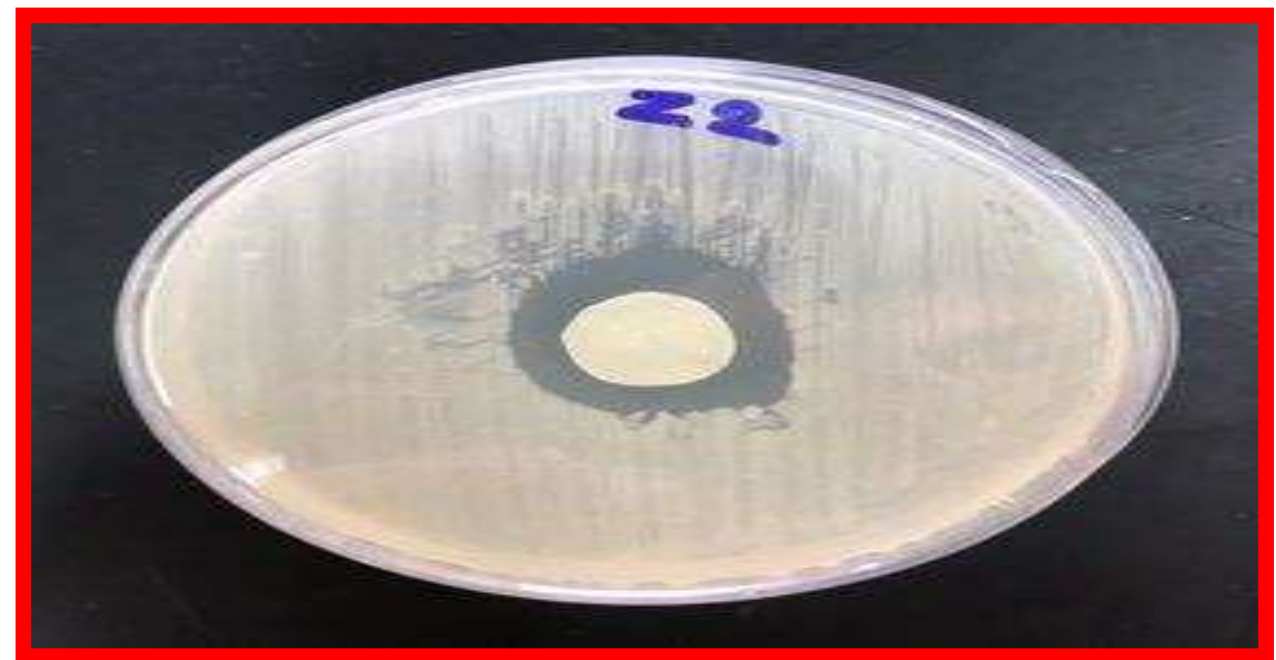

Figure 7-The inhibition zone of ZAK against Staphylococcus lentus growth onMuller-Hinton agar 


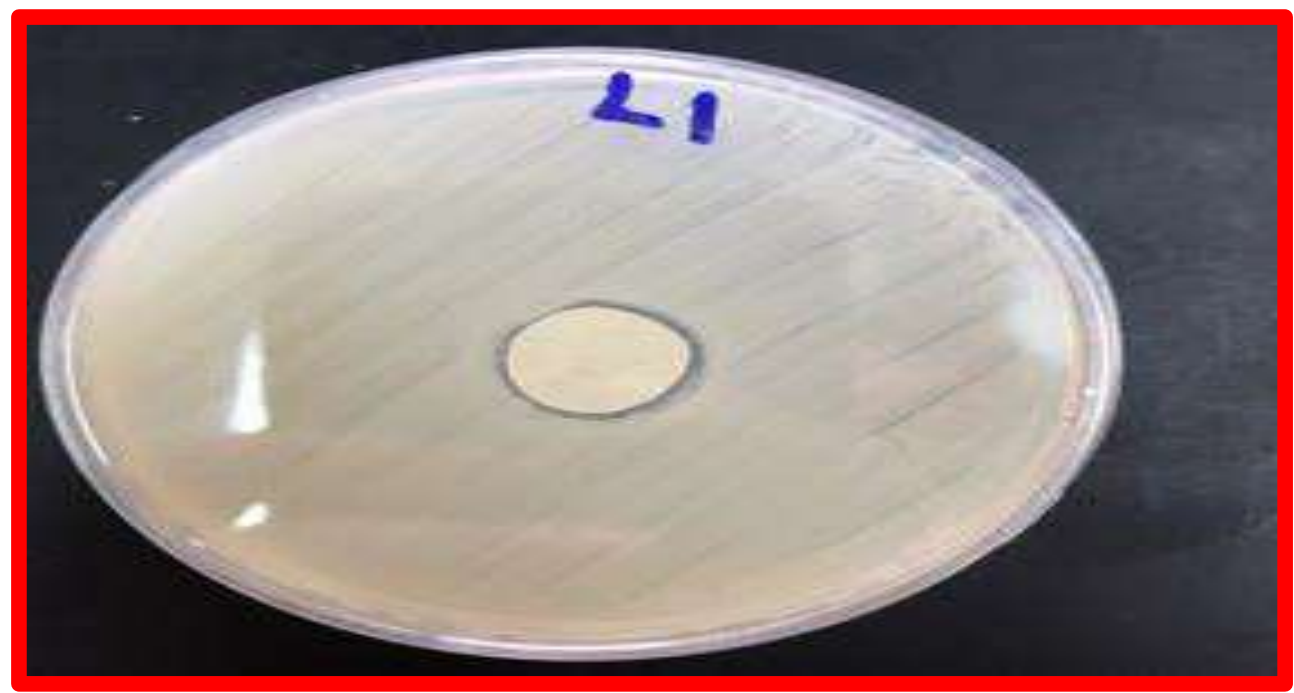

Figure 8- The inhibition zone of Listerine against Staphylococcus lentus growthonMuller-Hinton agar

The differences in theeffects of mouthwash solutions may be due to the differences in the chemical compositions.Colgate solution is composed of sodium fluoride $0.05 \%$, cetylpyridinium chloride and phenols conjugated with essential oils (eucalyptol, thymol, menthol and methyl salicylate in up to $26 \%$ alcohol). ZAK solution components includechlorhexidine gluconate and phenols conjugated with essential oils (eucalyptol, thymol, menthol and methyl salicylate in up to $26 \%$ alcohol). Listerine solution consists of only phenols conjugated with essential oils (eucalyptol, thymol, menthol and methyl salicylate in up to $26 \%$ alcohol).

\section{Mechanisms of action of active ingredients}

1. Chlorhexidine gluconate: It is a form of cationic bis-guanide which has a broad spectrum of antimicrobial activities against large extent of vegetative bacteria (Gram-positive and Gram-negative), some fungi and some viruses. The action mode on bacteria depends on the binding of this molecules (positively-charged) to a locus of another molecules (negatively-charged) which is located on the cell wall. This conjugation leads to destabilization of the cell wall and intervenes with osmosis. At this point the cell wall will be damaged and permitschlorhexidine to penetrate into the cell and attacks the cytoplasmic membrane, leading to disruption and damaging to the semipermeable membrane functions and allowing for components leakage which causes death to the cell [12].

2. Fluoride: The tooth enamel hydroxyapatite is originally composed of phosphate ions (PO43-) and calcium ions $(\mathrm{Ca} 2+)$. Under ordinary situation, there is a stable equilibrium between the crystalline hydroxyapatite that comprises $96 \%$ of tooth enamel with the calcium and phosphate ions in saliva [13]. The acidic environment on the tooth surface result in the combination of phosphate that occurs in the oral fluids with hydrogen ions $(\mathrm{H}+)$ to form a species of hydrogen phosphate. Phosphate under these conditions is "pulled" from tooth enamel in order to restore levels of phosphate in the saliva and the hydroxyapatite dissolves in a procedure called demineralization. In case of using fluoride, the calcium and phosphate in saliva can be recrystallized into the fluorapatite rather than hydroxyapatite during the remineralization process. Fluoride ions $(\mathrm{F}-)$ exchange hydroxyl groups $(\mathrm{OH}-)$ to form fluorapatite which is less soluble than hydroxyapatite and also more resistant to subsequent demineralization under acid challenge. The rate of remineralization, in fact, increases in the presence of fluoride [14] [15].

3. Phenols and essential oils: Mouthwashes contain four phenol-conjugated essential oils (eucalyptol, thymol, menthol and methyl salicylate in up to 26\% alcohol). Their action mode leads to the destruction of the bacterial cell, which happenseither by the inhibition of bacterial enzymes or the extraction of Gram-negative bacterial endotoxin [16].

4. Cetylpyridinium chloride: It is a compound of quaternary ammonium (cationic) with antiseptic and antimicrobial functions. It can bind to bacterial surfaces leading to disruption of the cell membrane, resulting in leakage to the intracellular components and metabolism disruption. Inhibition and reduction of plaque build-up could be achieved by mouthwashes containing cetylpyridinium chloride [16]. 


\section{Conclusions}

The study revealed that both Colgate and ZAK mouthwash solutions have antibacterial activities against the gram positive bacteria S.lentus, compared with Listerine which showed no or very weak inhibition activity, and that these differences are related to the differences in the chemical compositions. These results indicate that not all mouthwashes have the same capacity of antibacterial activity, and that some of them might not have such activity at all .

\section{Recommendation}

According to the results of our study we recommendthat Lesterine solution should not be used for mouth gargling and, instead, Colgate or ZAK solution could be used.

\section{References}

1. Batabyal, B., Chakraborty, S. and Biswas, S. 2012. Role of the oral microflora in human population: a brief review. IJPLS; 3(12): 2220- 2227.

2. Adams D. and Addy M. 1994. Mouthrinses. Adv Dent Res; 8: 291-301.

3. Academy of General Den 2017. Daily Tips for Good Oral Hygiene Accessed. https://www.manipalhospitals.com/our-specialities/dental-medicine/dental-plaque. https://www.webmd.com/oral-health/guide/plaque-and-your-teeth.

4. Patil S., Hombai L., Sanikop Sh. and Hebbal M. 2011. Is Mouthwash an Eyewash??? A Review. Journal of the Indain Association of Public Health Dentistry: 18(Suppl III): 928- 933.

5. HoltJ, G., Krieg, N.R., Sneath, PH.A., staley, J.T. and Williams, S.T. 1994. Bergey's Manual of Determinative Bacteriology, Ninth Edition,William\&Wilkins, Baltimore.Group 17,Gram-positive Cocci,527-558.

6. Srdjan Ste panovic, Ivana Dakic, Donald Morrison, Tomasz Hauschild, Petr Jezek, Petr Petrás, An Martel, Dragana Vukovic, Adebayo Shittu,and Luc A. 2005. Devriese: Identification and Characterization of Clinical Isolates of Members of the Staphylococcus sciuri Group. Journal of Clinical Microbiology, February, 43(2): 956-958

7. Stepanović S., Dakić I., Martel A., Vaneechoutte M., Morrison D., A., Ježek P., Decostere, A, Devriese, L. and Haesebrouck, F. 2005. "A comparative evaluation of phenotypic and molecular methods in the identification of members of the Staphylococcus sciuri group". Systematic and Applied Microbiology DO1:10.1016/.syapm. (4): 353-357.

8. Schwendener S. and Perreten V. 2012. New MLSB resistance gene erm (43) in Staphylococcus lentus. Antimicrobial agents and chemotherapy. 2012; 56: 4746-52.

9. Dakic, I., Morrison, D., Vukovic, D., Savic, B. 2005. Isolation and molecular characterization of Staphylococcus sciuri in the hospital environment. Journal of clinical microbiology, 43: 2782-5.

10. McDonnell, Gerald and A. Denver Russell 1999. "Antiseptics and Disinfectants: Activity, Action and Resistance."Clinical Microbiology Reviews, 12(1): 147-79. Print.

11. Featherstone JD. The caries balance 2004. The basis for caries management by risk assessment. Oral Health Prev Dent; 2(Suppl 1): 259-64.

12. Cury, JA. and Tenuta, LM. 2009. Enamel remineralization: controlling the caries disease or treating early caries lesions. Braz Oral Res; 23(Suppl 1): 23-3.

13. Tenuta LM. and Cury JA. 2010. Fluoride: its role in dentistry. Braz Oral 21Res. 24(Suppl 1):9-17.

14. Martin A. 2000. Oral hygiene products: Potential for harm to oral and systemic health? ; Periodontology, 48: 54-65.

15. Farah S. Camile, McIntosh Lidija, Michael J McCullough 2009. Mouthwashes. Australian Prescriber; 3(6): 162-164.

16. Mhaske Maya, Samad Nazish Baig, Jawade Rashmi and Bhansali Ashok. 2012. Chemical agents in control of dental plaque in dentistry: An overview of current knowledge and future challenges. Advances in Applied Science Research; 3(1): 268-272. 